\title{
Workfare, Monitoring, and Efficiency Wages
}

\author{
Christian Holzner, Volker Meier, and Martin Werding* \\ Ifo Institute for Economic Research \\ Poschingerstr. 5 \\ D-81679 Munich \\ Germany \\ E-mail: holzner@ifo.de; meier@ifo.de; werding@ifo.de \\ June 7, 2006
}

\begin{abstract}
The impact of a stronger work requirement for welfare recipients in a workfare program is studied in an efficiency wage model where a representative firm chooses its level of monitoring activities. A stricter workfare policy raises employment and monitoring activities. It typically increases profits and reduces the tax rate. The impact on the net wage is ambiguous. Utility levels of employed workers and welfare recipients may increase even if the net wage declines. The utility differential between these two groups of workers shrinks.
\end{abstract}

JEL classification: H53; J41; J60

Keywords: Workfare; Welfare; Efficiency wages; Monitoring

${ }^{*}$ We would like to thank the German Research Foundation (DFG) for financial support under grant No. WE 2815/1-1. 


\section{Introduction}

Throughout the world, welfare recipients are faced with the obligation to work in exchange for the cash benefits they receive. This combination of paying welfare benefits and demanding a work effort has been coined "workfare". Considering that in many cases the output in such programs has been quite low, many countries have refrained from actually using workfare. However, enforcing the work requirement on a large scale constitutes one of the core elements of the US welfare reform in the last decade (see the surveys by Ellwood, 2000, Haveman and Wolfe, 2000, Blank, 2002, and Moffitt, 2002). Interestingly, the number of welfare recipients in the US has fallen drastically in the last few years (Hotz et al., 2002).

Our paper addresses the impacts of introducing and enforcing workfare institutions on employment, wages, profits, and utility levels of both employed and unemployed workers. A framework of involuntary unemployment is chosen in which the effects of workfare are independent of behavioral changes of welfare recipients. If jobs were available, welfare recipients would reduce their reservation wage when being asked to enter a workfare program, causing an increase in employment. In our setting, labor demand reacts to the changes of the incentive structure of the employed, who perceive the risk of a dismissal as a more severe threat. Forward-looking welfare recipients may be compensated for the required work effort by better job opportunities.

We analyze an efficiency wage model in which workers can choose to shirk. For simplicity, all unemployed are taken to be welfare recipients, and benefits are financed by a proportional income tax. A representative firm chooses its monitoring intensity at the workplace, that is, the share of workers engaged in supervising their co-workers. The workfare program itself may also be associated with a monitoring cost for ensuring that the participants do not shirk. All individuals are identical with respect to abilities and preferences.

Strengthening the work requirement for welfare recipients will increase both employment and the monitoring intensity, and generally lowers both taxes and wages. As being unemployed becomes more uncomfortable, wages can be reduced, increasing the demand for labor and reducing the opportunity cost of monitoring. Taxes then go down along with a declining welfare caseload. Profits will increase with more productive employment, 
while the impact on net wages is ambiguous. Expected lifetime utility levels of employed and unemployed may increase even if the net wage falls. The unemployed lose according to their increased disutility of labor, while they benefit through improved job opportunities. The chances to re-enter employment are further increased due to the fact that the higher monitoring intensity within firms diminishes the rent of employed workers, thus inducing an additional wage cut. The smaller utility differential reduces losses arising from exogenous splits of employment relationships. The results indicate that imposing workfare can even lead to a Pareto improvement.

The theoretical literature on workfare programs has extensively dealt with screening issues. Workfare has been justified with the objective to achieve a minimum utility level or a minimum income of social assistance recipients by Dye and Antle (1986), Blackorby and Donaldson (1988), and Besley and Coate (1992). Further, Chambers (1989), Besley and Coate (1995), Brett (1998) and Cuff (2000) have explored the efficiency properties of workfare designs under voluntary unemployment within an optimum income tax framework. The basic idea is that individuals with high earnings capacities are deterred from taking up benefits. In a dynamic perspective, the less comfortable treatment of the unemployed creates an incentive to acquire human capital.

The consequences of workfare on the participants are subject to disputes. While Coate (1995) stresses that the work requirement may reduce future welfare dependency, Peck and Theodore (2000) argue that human capital losses arise if training is crowded out by the work requirement. A public-choice argument for the widespread acceptance of workfare rules has been offered by Moffitt (1999). Combining a high income of the poor with a work requirement may simply reflect the preferences of the political majority. These voters will then be willing to finance unproductive workfare programs.

Surprisingly little has been said about welfare effects in a general equilibrium context. Solow (1998) stresses that measures reducing the well-being of welfare recipients will usually lead to an increase in employment. However, he suspects that low-skilled workers will be the losers of such reforms due to falling wages. Schöb (2003) arrives at similar results for a scenario where a monopolistic union sets the wage rate. Within a matching model, Fredriksson and Holmlund (2003) confirm the argument of Thustrup Kreiner and Tranæs (2005), stating that workfare can bring about a Pareto improvement by screening the voluntarily unemployed and allowing for an increase in the replacement rate in unemploy- 
ment insurance. In their view, the drawback of workfare vis-à-vis the introduction of time limits or a stricter monitoring of search activities lies in that it provides little incentives for job search. Meier (2002) shows for a shirking model with exogenous monitoring that net wages and lifetime utilities of employed and unemployed workers all move into the same direction. Hence, it is not obvious that workfare affects employed and unemployed workers asymmetrically.

The remainder of the paper is organized as follows. After introducing the model in section 2, section 3 analyzes the problems of existence and stability of equilibria. Comparative static results are derived in section 4 . Section 5 discusses the results and indicates directions for future research.

\section{The Model}

The model is based on Shapiro and Stiglitz (1984). We consider $N$ identical workers whose preferences are described by the utility function $U(\omega, \varepsilon)=\omega-\varepsilon$, where $\omega$ denotes the monetary compensation and $\varepsilon$ is the effort exerted at the workplace. With probability $b$ per unit of time, an employment relationship breaks down for exogenous reasons. Workers are infinitely lived and maximize $W=E \int_{0}^{\infty} U(\omega(s), \varepsilon(s)) \exp (-r s) d s$, where $s$ denotes time, $r>0$ is the discount rate, and $E$ represents the expectations operator. Employed workers can either shirk $(e=0)$ or choose the expected effort level $(e=1)$. Workers who shirk are detected with probability $q$ per unit of time. Detected shirkers are laid off immediately.

The unemployed have to participate in a workfare program in order to receive the benefit $\bar{w}>0$. We disregard the possibility that some of the unemployed may prefer a cut of the benefit even if it goes down to zero. The net cost of monitoring a participant to prevent him from shirking, accounting for a possible positive value of the output, is given by $m$. The study of Haveman and Wolfe (2000), reporting strong increases in monthly cost per family upon introducing the workfare program in Wisconsin, indicates substantial costs of organizing public jobs and enforcing the work obligation. The disutility of work required in the program is reflected by the effort $e_{u}$. Recalling that in real world programs the unemployed can choose to opt out, we assume that $e_{u} \leq e$, that is, the effort required in the workfare program does never exceed the effort required at the workplace. Welfare 
benefits are financed by a proportional income tax with $t$ denoting the tax rate. The net wage $(1-t) w$ of an employed worker will always be set such that it exceeds the welfare benefit $\bar{w}$.

Let $V_{E}^{S}, V_{E}^{N}$, and $V_{u}$ denote expected lifetime utility of an employed shirker, employed non-shirker, and unemployed individual, respectively. The asset equations for shirkers and non-shirkers are given by

$$
r V_{E}^{S}=(1-t) w+(b+q)\left(V_{u}-V_{E}^{S}\right)
$$

and

$$
r V_{E}^{N}=(1-t) w-e+b\left(V_{u}-V_{E}^{N}\right) .
$$

These equations state that the return in each period is equal to the sum of the flow benefit and the expected change of the value of the asset. An employed worker will not shirk if $V_{E}^{S} \leq V_{E}^{N}$, being equivalent to the no-shirking condition

$$
(1-t) w \geq r V_{u}+\frac{(r+b+q) e}{q}
$$

The representative firm produces under decreasing returns. Its output is given by $Q=F\left(L_{P}\right)$ where $L_{P}$ denotes the number of employed production workers who are not shirking. The production function satisfies $F^{\prime}\left(L_{P}\right)>0, F^{\prime \prime}\left(L_{P}\right)<0$ and $F^{\prime}(N)>e$. The last property implies that full employment would be efficient.

An unemployed worker always participates in the workfare program. He gets a new job with probability $\alpha$ per unit of time. The asset equation of an unemployed worker is given by

$$
r V_{u}=\bar{w}-e_{u}+\alpha\left(V_{E}-V_{u}\right)
$$

with $V_{E}=\max \left\{V_{E}^{S}, V_{E}^{N}\right\}$. If not shirking at the workplace is optimal, (2) and (4) can be solved. We obtain

$$
\begin{gathered}
V_{E}-V_{u}=\frac{(1-t) w-\bar{w}-\left(e-e_{u}\right)}{r+\alpha+b} \\
r V_{u}=\bar{w}-e_{u}+\alpha \frac{(1-t) w-\bar{w}-\left(e-e_{u}\right)}{r+\alpha+b} \\
r V_{E}=(1-t) w-e-b \frac{(1-t) w-\bar{w}-\left(e-e_{u}\right)}{r+\alpha+b} .
\end{gathered}
$$


Inserting (6) into the no-shirking condition yields

$$
(1-t) w \geq \bar{w}+e-e_{u}+\frac{r+\alpha+b}{q} e .
$$

Inducing workers not to shirk requires a higher wage $w$ if either the welfare benefit $\bar{w}$ gets higher, the rate of exogenous splits $b$ increases, the rate of obtaining a new job $\alpha$ goes up, the tax rate $t$ increases, the rate of time preference $r$ rises or the quality of shirking detection, as measured by $q$, falls. The inequality (8) indicates that $(1-t) w-e>\bar{w}-e_{u}$ must hold to deter shirking. By (6) and (7), employed workers have a higher expected remaining lifetime utility than those who are unemployed at any given point in time. Thus, unemployment is involuntary. Employed workers earn the information rent $\frac{r+\alpha+b}{q} e$ due to the fact that the shirking detection technology is imperfect, that is, $q$ is finite.

The detection technology is endogenized as follows. Let $L_{S}$ denote the number of workers who are engaged in monitoring. The number of productive workers is $L_{P}=L-L_{S}$, and $L$ is total employment. The shirking detection rate $q$ depends on the share of monitoring labor at the workplace. Thus, $q=H(\sigma)$, with $\sigma:=\frac{L_{S}}{L}$, where the detection function $H$ exhibits diminishing returns $\left(H^{\prime}>0, H^{\prime \prime}<0\right)$ and satisfies the Inada conditions, $\lim _{\sigma \rightarrow 0} H^{\prime}=\infty$ and $\lim _{\sigma \rightarrow 1} H^{\prime}=0$. Monitoring workers and productive workers receive the same wage, and monitoring workers control each other. Their shirking decision is identical to the shirking decision of productive workers. The firm maximizes net profits subject to the no-shirking condition. The Lagrangian is given by

$$
\Lambda=(1-t)[F((1-\sigma) L)-w L]+\lambda\left[(1-t) w-\bar{w}-e+e_{u}-\frac{r+\alpha+b}{H(\sigma)} e\right],
$$

with $\lambda$ denoting the Lagrange multiplier associated with the no-shirking constraint. Optimizing with respect to total employment $L$, the monitoring intensity $\sigma$, the gross wage $w$, and $\lambda$ yields the first-order conditions

$$
\begin{aligned}
& \frac{\partial \Lambda}{\partial L}=(1-t)\left[(1-\sigma) F^{\prime}-w\right]=0, \\
& \frac{\partial \Lambda}{\partial \sigma}=-(1-t) L F^{\prime}+\lambda e \frac{r+\alpha+b}{[H(\sigma)]^{2}} H^{\prime}=0, \\
& \frac{\partial \Lambda}{\partial w}=-(1-t) L+\lambda(1-t)=0, \\
& \frac{\partial \Lambda}{\partial \lambda}=(1-t) w-\bar{w}-e+e_{u}-\frac{r+\alpha+b}{H(\sigma)} e=0 .
\end{aligned}
$$


The optimality conditions can be interpreted as follows. Equation (9) states that additional workers will be hired until the marginal productivity of labor, corrected for losses through unproductive monitoring, is equal to the gross wage. According to (10), a higher monitoring intensity is associated with a profit reduction of $(1-t) L F^{\prime}$ because more labor becomes unproductive. On the other hand, as indicated by $\lambda e \frac{r+\alpha+b}{[H(\sigma)]^{2}} H^{\prime}$, the no-shirking constraint is no longer binding. This can be exploited to increase profits by cutting the wage. Last, a higher wage directly increases labor costs. Again, the firm benefits according to $\lambda(1-t)$ because the no-shirking constraint is no longer binding. This effect could be used to raise profits by reducing the monitoring intensity. It is easy to see that, with the employment level and monitoring intensity being given, the wage will be chosen so as to satisfy the no-shirking condition with equality. From the firm's perspective, the tax rate $t$ and the reemployment rate $\alpha$ represent parameters. Lemma 1 shows that the firm's optimization problem has a unique solution.

Lemma 1 At a given tax ratet and reemployment rate $\alpha$, an optimum vector $\left(\sigma^{*}, L^{*}, w^{*}\right)>$ 0 , consisting of monitoring intensity $\sigma^{*}$, employment $L^{*}$, and wage $w^{*}$, exists and is unique.

Proof. See Appendix A.

In equilibrium, the number of entries into unemployment is equal to the number of exits:

$$
\alpha(N-L)=b L
$$

Substituting for $\alpha$ in the no-shirking condition leads to

$$
(1-t) w \geq \bar{w}+e-e_{u}+\frac{r}{q} e+\frac{b}{q} e \frac{1}{u}
$$

$u=\frac{N-L}{N}$ representing the unemployment rate. At $L=0$, the right-hand side of (14) is equal to $\bar{w}-e_{u}+\frac{r+b+q}{q} e$. It increases in $L$ and goes to infinity if $L \rightarrow N$.

If workers do not shirk, the representative firm will set its labor input to the point where the marginal product of labor, corrected for losses through monitoring, is equal to the gross wage, that is, $w=(1-\sigma) F^{\prime}((1-\sigma) L)$. Utilizing this relationship and the government budget equation

$$
t F((1-\sigma) L)=(\bar{w}+m)(N-L)
$$


implies that feasible allocations require

$$
(1-t) w=(1-\sigma) F^{\prime}((1-\sigma) L)\left(1-\frac{\bar{w}+m}{F((1-\sigma) L)}(N-L)\right)
$$

Note that the right-hand side of $(16)$ is equal to $F^{\prime}((1-\sigma) N)>0$ if $L=N$. Moreover, provided that $F(0)=0$, an employment level $L_{0} \in(0, N)$ exists which satisfies $(1-$ $\left.\frac{\bar{w}+m}{F((1-\sigma) L)}(N-L)\right)=0$.

All relevant decisions are taken simultaneously. The government always adjusts the tax rate instantaneously so as to balance its budget. The firm generally takes as given both the wage and the tax rate, and chooses the employment level and the monitoring intensity so as to maximize profits. However, the firm accepts underbidding by unemployed workers if net wages are higher than necessary to satisfy the no-shirking constraint. Conversely, should the net wage be too low to prevent shirking, the firm will increase the gross wage. Taking as given wages, policy variables, and the unemployment rate, employed workers choose whether or not to shirk.

\section{Equilibria and Stability}

The model can be simplified to a system of two equations for $\sigma$ and $L$. Combining the first-order condition for the optimum monitoring intensity, (10), with the labor market equilibrium condition (13) and the budget equation (15), where the Lagrange multiplier can be derived from (11), yields

$$
f_{1}=-\left(1-\frac{(\bar{w}+m)(N-L)}{F((1-\sigma) L)}\right) F^{\prime}((1-\sigma) L)+e \frac{r+b \frac{N}{N-L}}{[H(\sigma)]^{2}} H^{\prime}(\sigma)=0 .
$$

Equation $f_{1}$ defines a relation $\sigma(L)$ which can exist for some $L$ in the range $\left(L_{\min }, N\right)$, where $L_{\min }$ is the minimum feasible employment where welfare benefits can be financed, that is, $F\left(L_{\min }\right)=(\bar{w}+m)\left(N-L_{\min }\right)$. The first term, $-\left(1-\frac{(\bar{w}+m)(N-L)}{F((1-\sigma) L)}\right) F^{\prime}((1-\sigma) L)$, represents the reduction in net profits through the marginal cost per employed worker

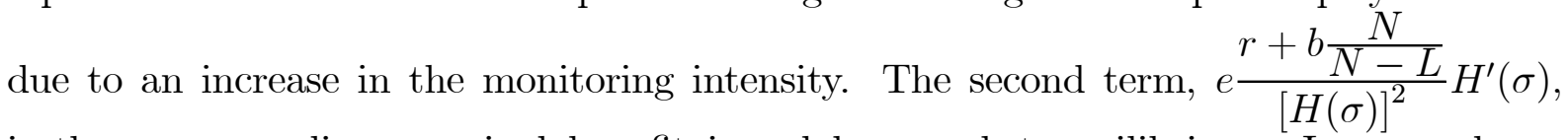
is the corresponding marginal benefit in a labor market equilibrium. In general, we have $\lim _{\sigma \rightarrow 0} f_{1}=\infty$ and $\lim _{\sigma \rightarrow \sigma_{\max }} f_{1}>0$, with $\sigma_{\max }$ denoting the maximum monitoring 
intensity being feasible, that is, $\frac{(\bar{w}+m)(N-L)}{F\left(\left(1-\sigma_{\max }\right) L\right)}=1$. Ignoring the possibility of a tangent point, there are usually at least two solutions for $\sigma$ that satisfy $f_{1}(\sigma, L)=0$. In Figure 1 , the equilibrium monitoring intensity $\sigma_{1}$ is stable, while $\sigma_{2}$ is unstable. For monitoring intensities close to the equilibrium values, the marginal benefit exceeds the marginal cost if $\sigma<\sigma_{1}$, implying that there is a tendency to increase the monitoring intensity, and vice versa. A stable equilibrium monitoring intensity requires that $f_{1 \sigma} \leq 0$ holds at any combination $(\sigma, L)$ that satisfies $(17)$.

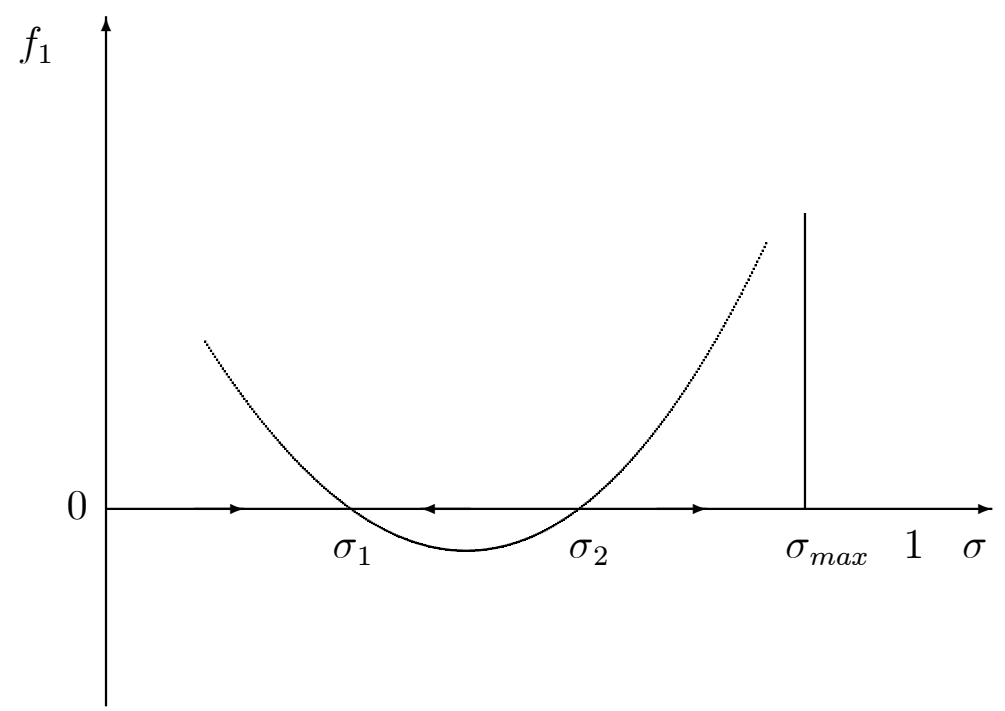

\section{I}

Fig. 1. Stable and unstable monitoring intensity

Combining the input rule (9) with the no-shirking condition (12), the labor market equilibrium condition (13), and the budget equation (15) gives us

$$
\begin{aligned}
f_{2}= & (1-\sigma) F^{\prime}((1-\sigma) L)\left[1-\frac{\bar{w}+m}{F((1-\sigma) L)}(N-L)\right] \\
& -\bar{w}-e+e_{u}-\frac{r+b \frac{N}{N-L}}{H(\sigma)} e \\
= & 0 .
\end{aligned}
$$

Equation $f_{2}$ describes a relation $L(\sigma)$ that generally exists in some range $\left(0, \sigma_{\max }\right)$, where $\sigma_{\max }$ is defined as above. The first term, $(1-\sigma) F^{\prime}((1-\sigma) L)\left[1-\frac{\bar{w}+m}{F((1-\sigma) L)}(N-L)\right]$, 
represents the marginal net revenue from increasing employment. In a labor market equilibrium, the remaining terms, $-\bar{w}-e+e_{u}-\frac{r+b \frac{N}{N-L}}{H(\sigma)} e$, are equal to $-(1-t) w$, that is, the corresponding net marginal cost. Note that $\lim _{L \rightarrow L_{\min }} f_{2}<0$ and $\lim _{L \rightarrow N} f_{2}=$ $-\infty$. Neglecting again the possibility of a tangent point, at least two solutions for $L$ exist that satisfy $f_{2}(\sigma, L)=0$. In Figure 2, the low equilibrium employment $L_{1}$ is unstable, while the high equilibrium employment $L_{2}$ is stable. For employment levels close to the equilibrium, we see that marginal revenue exceeds marginal cost if $L<L_{2}$, implying that there is a tendency to increase employment, and vice versa. A stable equilibrium employment requires that $f_{2 L} \leq 0$ holds at the candidate vector $(\sigma, L)$ satisfying $(18)$.

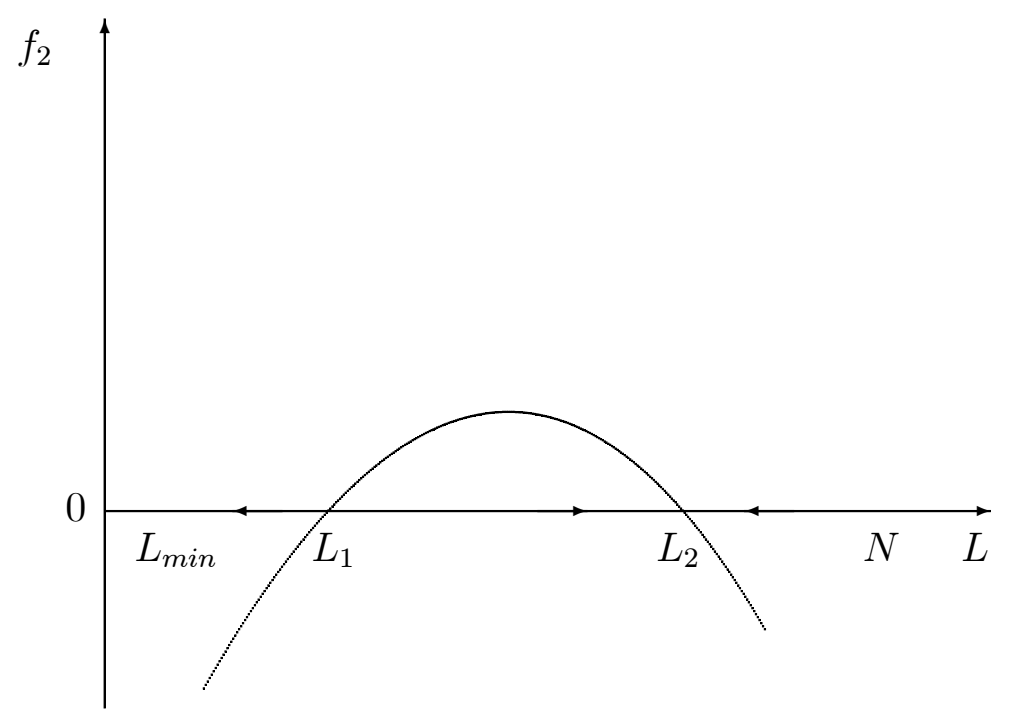

Fig. 2. Stable and unstable equilibrium employment

An equilibrium is a vector $(\bar{\sigma}, \bar{L})$ that satisfies both (17) and (18). The dynamics of the monitoring intensity and aggregate employment is described by

$$
\begin{aligned}
\dot{\sigma} & =h_{1}\left(f_{1}(\sigma, L)\right), \\
\dot{L} & =h_{2}\left(f_{2}(\sigma, L)\right),
\end{aligned}
$$

with $h_{1}(0)=h_{2}(0)=0, h_{1}^{\prime}>0$, and $h_{2}^{\prime}>0$. Thus, firms increase the monitoring intensity or employment, respectively, if the marginal benefit outweighs the marginal cost. 
Taking these pieces together, Figure 3 shows a typical situation that may emerge. The upper branch of the $f_{1}=0$ curve is related to unstable equilibrium monitoring intensities and the left branch of the $f_{2}=0$ curve represents unstable equilibrium employment levels. Among the four vectors of monitoring intensity and employment that satisfy both equations, only $\left(\sigma_{1}, L_{1}\right)$ is locally asymptotically stable.

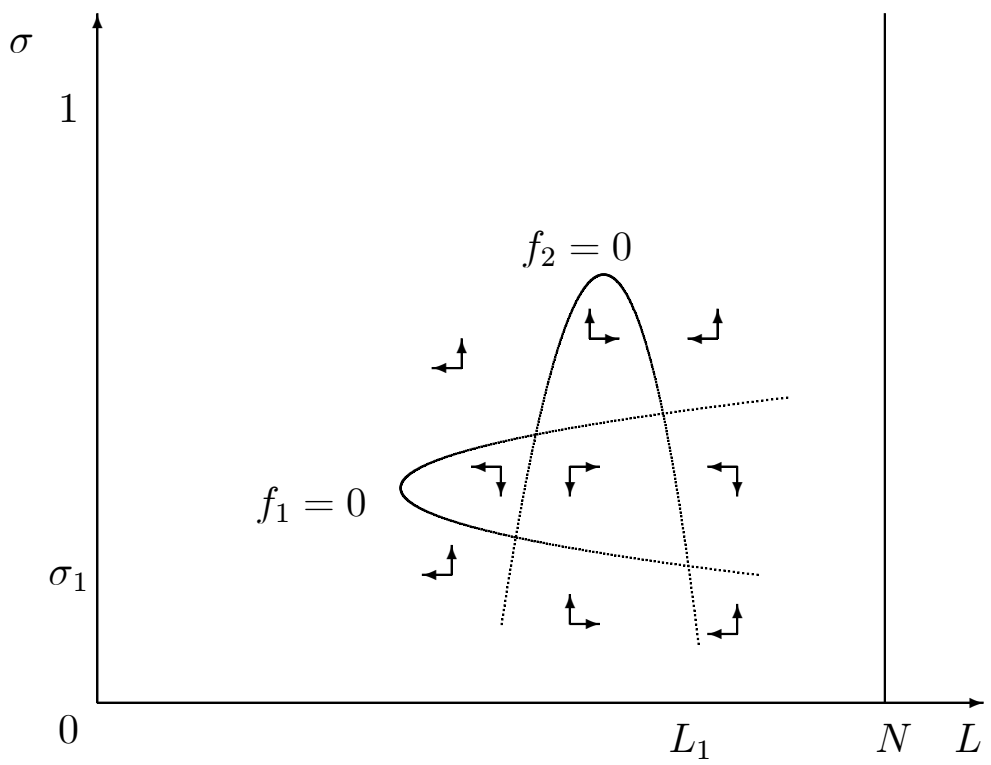

Fig. 3. Stable and unstable branches

In the following, we confine our attention to the stable branches and, therefore, treat both $\sigma(L)$ and $L(\sigma)$ as functions, corresponding to the equilibrium conditions $f_{1}$ and $f_{2}$. Lemma 2 demonstrates that a third condition has to be satisfied to ensure local asymptotic stability.

Lemma 2 An equilibrium $(\bar{\sigma}, \bar{L})$ is locally asymptotically stable only if $f_{1 \sigma} f_{2 L}-f_{1 L} f_{2 \sigma} \geq 0$ holds at $(\bar{\sigma}, \bar{L})$.

Proof. See Appendix B. 


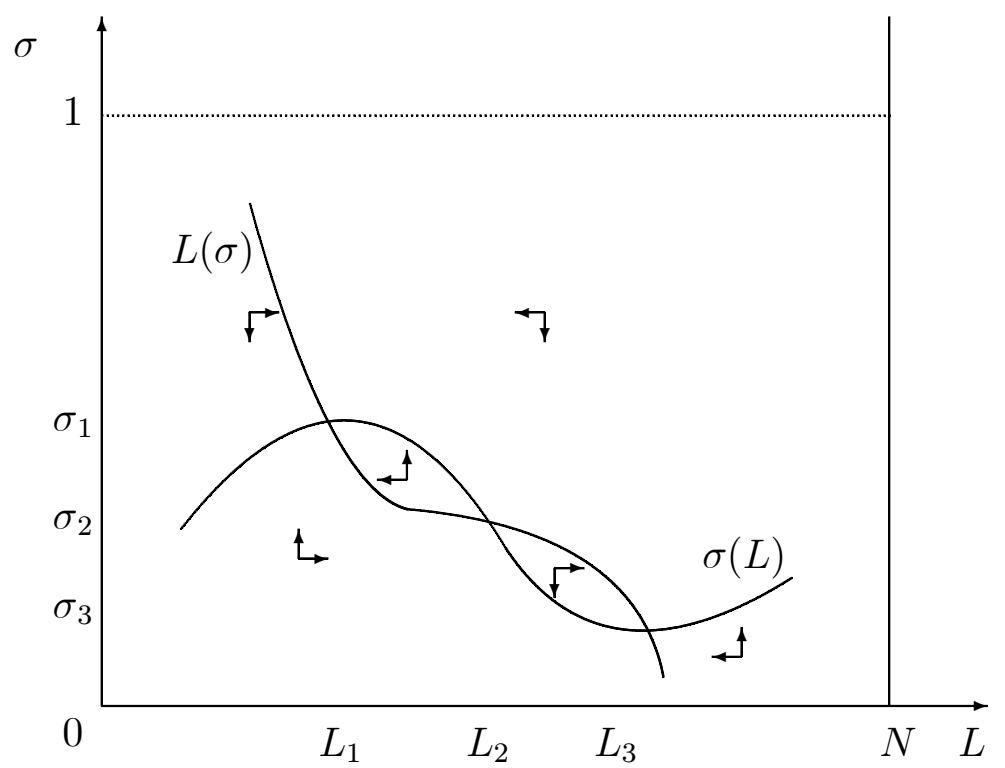

Fig. 4. Stable and unstable equilibria (i)

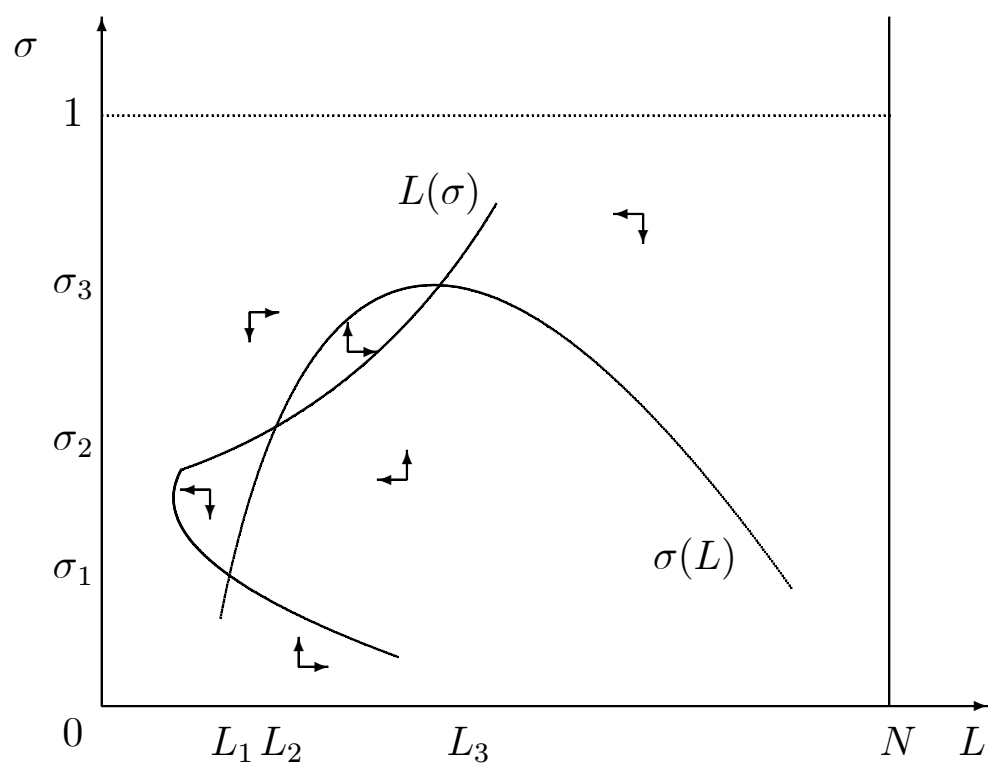

Fig. 5. Stable and unstable equilibria (ii) 
It should be noted that all equilibria satisfying $f_{1 \sigma}<0, f_{2 L}<0$ and $f_{1 \sigma} f_{2 L}-f_{1 L} f_{2 \sigma} \geq 0$ are locally asymptotically stable. Further, if the equilibrium based on stable branches is unique, it will also be stable. In Figures 4 and 5 , the equilibria $\left(\sigma_{1}, L_{1}\right)$ and $\left(\sigma_{3}, L_{3}\right)$ are locally stable, whereas this is not the case for the equilibrium $\left(\sigma_{2}, L_{2}\right)$.

\section{Comparative statics}

Assuming that a unique stable equilibrium $(\bar{\sigma}, \bar{L})$ exists, we can now investigate the impact of a change in the work requirement $e_{u}$ on the endogenous variables. Our analysis starts by considering the effects that arise at the micro level, neglecting repercussions on the reemployment rate $\alpha$ and the tax rate $t$. For given macro variables, the reactions of the firm to a stricter work requirement in the workfare program are described in Proposition 1.

Proposition 1 At a given tax ratet and reemployment rate $\alpha$, a stricter work requirement in the workfare program $e_{u}$ induces the representative firm to increase the monitoring intensity $\sigma$, total employment $L$, and productive employment $(1-\sigma) L$, while the wage $w$ is reduced.

Proof. See Appendix C.

With a stricter work requirement, the no-shirking constraint is no longer binding. This enables the firm to reduce the wage and to hire more labor. At a given marginal productivity of labor utilized for production ("productive labor"), the higher employment level raises both the marginal cost and the marginal benefit of an increase in the monitoring intensity. These two effects just offset each other. At the same time, the wage cut reflected in the smaller marginal productivity of productive labor decreases the opportunity cost of monitoring. Therefore it pays to raise the monitoring intensity. In the new optimum, employment of productive labor will be higher because otherwise the incentive to raise the monitoring intensity would not exist.

Noting that the direct reactions create more jobs and decrease the number of welfare recipients, the reemployment rate will increase and the tax rate will fall. The reactions of the firm to changes in these parameters are summarized in Proposition 2. 
Proposition 2 At a given tax rate $t$, the representative firm reacts to an increasing reemployment rate $\alpha$ by increasing both the control intensity $\sigma$ and the gross wage $w$, and by reducing productive employment $(1-\sigma) L$. At a given job acquisition rate $\alpha$, a lower tax rate $t$ induces the firm to decrease the gross wage $w$ and to raise employment $L$, while keeping both the monitoring intensity $\sigma$ and the net wage $(1-t) w$ constant.

Proof. See Appendix D.

A higher job acquisition rate increases the marginal benefit of monitoring due to a stronger incentive to shirk. This effect works in favor of raising the monitoring intensity. The wage rate will also rise in order to satisfy the no-shirking condition again. The higher wage rate increases the cost of labor, while the higher monitoring intensity is associated with productivity losses. Profit maximization then requires a higher marginal productivity of productive labor, which can only be achieved by employing a smaller number of productive workers.

A falling tax rate reduces the incentive to shirk. This creates a pressure on the wage rate and the monitoring intensity. At the same time, the loss of net revenue that arises through monitoring becomes larger, again implying a tendency towards less monitoring. The falling cost of labor induces the firm to hire more workers. Recalling the interpretation of Proposition 1, the net effect of a higher employment level on the monitoring intensity is positive. It turns out that incentives are restored by cutting the wage and keeping the monitoring intensity constant. The reduction of the marginal productivity of productive labor due its higher utilization just offsets the falling tax rate. Since the opportunity cost of increasing the monitoring intensity remains constant, the various impacts on the monitoring intensity are neutralized.

We proceed by investigating the impact of a stricter work requirement in the workfare program in equilibrium.

Proposition 3 A higher disutility of participants in the workfare program, $e_{u}$, increases both employment $L$ and the monitoring intensity $\sigma$. The lifetime utility differential between employed and unemployed workers, $V_{E}-V_{u}$, shrinks.

Proof. See Appendix E. 
The results are easily understood based on Propositions 1 and 2. Due to the stricter work requirement for welfare recipients, the no-shirking condition is no longer binding. Firms respond by reducing the gross wage and by hiring more labor. Since the net impact on the opportunity cost of monitoring is negative, it turns out to be profitable to increase the monitoring intensity. With higher labor demand and a smaller number of welfare recipients, the tax rate goes down and the chances of obtaining a job are improved. The falling tax rate yields a further increase in employment, while keeping the monitoring intensity unaffected. The falling unemployment rate again drives up the optimum monitoring intensity. Hence, the impact on the monitoring intensity is unambiguously positive.

In contrast to Meier (2002), there is a distributive impact on workers in terms of absolute lifetime utility differentials. The utility differential shrinks due to the rising monitoring intensity, reducing the information rent of employed workers.

We show in Appendix $\mathrm{F}$ that productive employment may change in either direction. As we view a potential decline as being quite implausible, we consider an increasing level of productive employment as the typical reaction in the following. Hence, we assume that the reduction in productive employment is never strong enough to offset, or even revert, the increases that occur (i) as a direct reaction to a stricter work requirement for welfare recipients and (ii) due to the fall of the tax rate.

The gross wage $w=(1-\sigma) F^{\prime}((1-\sigma) L)$ will obviously always fall if productive employment does not decrease. Profits can be written as

$$
\pi=F((1-\sigma) L)-L(1-\sigma) F^{\prime}((1-\sigma) L)
$$

They increase if and only if productive employment goes up,

$$
\frac{\partial \pi}{\partial(1-\sigma) L}=-(1-\sigma) L F^{\prime \prime}((1-\sigma) L)>0
$$

The change in the tax rate is given by

$$
\frac{\partial t}{\partial e_{u}}=\frac{\bar{w}+m}{F^{2}}\left[-F \frac{\partial L}{\partial e_{u}}-(N-L) F^{\prime} \frac{\partial(1-\sigma) L}{\partial e_{u}}\right] .
$$

The tax rate will generally fall due to both a smaller number of welfare recipients and a higher total output. The latter is a consequence of the increasing productive labor input. 
Taking into account the equilibrium condition (17), the change in the net wage can be derived as

$$
\begin{aligned}
\frac{\partial(1-t) w}{\partial e_{u}}= & e\left[\frac{(1-\sigma) b N H^{\prime}}{H^{2}(N-L)^{2}} \frac{\partial L}{\partial e_{u}}\right. \\
& \left.+\left(r+b \frac{N}{N-L}\right) \frac{(1-\sigma)\left[H^{\prime \prime} H-2\left(H^{\prime}\right)^{2}\right]-H^{\prime} H}{H^{3}} \frac{\partial \sigma}{\partial e_{u}}\right] .
\end{aligned}
$$

The change in the net wage is ambiguous in sign. While the combination of a higher monitoring intensity and a rising level of productive employment contributes to a falling gross wage, the tax cut works in the opposite direction. The positive impact of rising employment on the net wage in equation (24) only captures the consequences of a higher reemployment rate. The ambiguity result is obvious when considering a scenario in which the monitoring intensity is almost fixed. This may happen if there is a kink or some similar structure in the function $H$ at the equilibrium monitoring intensity. When the program cost per unemployed worker $\bar{w}+m$ is sufficiently small, say zero, the reduction of the gross wage due to a higher utilization of productive labor must be the dominating effect. By contrast, when the program cost $\bar{w}+m$ is substantial, while the elasticity of the marginal product of labor with respect to labor input is close to zero, the tax cut will induce a rising net wage.

In terms of per period utility, the impact on welfare of the two groups of workers are described by

$$
\frac{\partial r V_{E}}{\partial e_{u}}=\frac{\partial(1-t) w}{\partial e_{u}}+\frac{b e H^{\prime}}{[H(\sigma)]^{2}} \frac{\partial \sigma}{\partial e_{u}}
$$

and

$$
\frac{\partial r V_{u}}{\partial e_{u}}=\frac{\partial(1-t) w}{\partial e_{u}}+\frac{(b+r) e H^{\prime}}{[H(\sigma)]^{2}} \frac{\partial \sigma}{\partial e_{u}} .
$$

It can easily be seen that both utility measures increase if the net wage remains constant. Lifetime utility of an employed worker can rise even if the net wage declines because the loss in utility triggered by a breakdown of the employment relationship falls.

\section{Conclusions}

It has been shown that introducing a workfare program bears the potential for a Pareto improvement. It increases employment and will generally raise profits and reduce gross 
wages. Productive employment usually increases as well as unproductive monitoring. The latter reduces the rent of employed workers, improving the chances of the unemployed to get a job. Interestingly, the unemployed would be the winners of the reform in terms of absolute utility differentials. Since the tax rate falls due to a higher output and a smaller number of unemployed, the net wage may move in either direction. A constant net wage would already be sufficient to achieve a higher expected lifetime utility for everybody. These results may explain why workfare experiments have become more popular during the last years.

Our model may be too optimistic with respect to the employability of the unemployed. Usually, welfare recipients display less favorable labor market characteristics than shortterm unemployed and show a substantially smaller exit rate into employment. It may therefore be the case that workfare for welfare recipients affects the unemployed in an asymmetric fashion. The impact on lifetime utility will then be positive for the shortterm unemployed, while it is negative for some groups of the long-term unemployed who are subjected to the workfare rule but still have only small chances of regaining employment. Therefore, introducing workfare measures without screening the candidates before imposing the work requirement should typically harm some of the poorest individuals. 


\section{Appendix}

\section{A: Proof of Lemma 1}

Isolating $\lambda$ in (11) and $F^{\prime}$ in (9), and inserting the results into (10) yields

$$
-(1-t) L \frac{w}{1-\sigma}+L e \frac{r+\alpha+b}{[H(\sigma)]^{2}} H^{\prime}=0
$$

Substituting for $(1-t) w$ from (12) then implies

$$
\begin{aligned}
\Psi(\sigma) & =-\frac{\bar{w}+e-e_{u}+\frac{r+\alpha+b}{H(\sigma)} e}{1-\sigma}+e \frac{r+\alpha+b}{[H(\sigma)]^{2}} H^{\prime} \\
& =e \frac{r+\alpha+b}{H(\sigma)}\left[\frac{H^{\prime}(\sigma)}{H(\sigma)}-\frac{1}{1-\sigma}\right]-\frac{\bar{w}+e-e_{u}}{1-\sigma} \\
& =0 .
\end{aligned}
$$

Note that $\lim _{\sigma \rightarrow 0} \Psi(\sigma)=\infty, \lim _{\sigma \rightarrow 1} \Psi(\sigma)=-\infty$, and

$$
\begin{aligned}
\Psi^{\prime}(\sigma)= & -\frac{\bar{w}+e-e_{u}}{(1-\sigma)^{2}}-e \frac{r+\alpha+b}{H(\sigma)} \frac{H^{\prime}(\sigma)}{H(\sigma)}\left[\frac{H^{\prime}(\sigma)}{H(\sigma)}-\frac{1}{1-\sigma}\right] \\
& +e \frac{r+\alpha+b}{H(\sigma)}\left[\frac{H^{\prime \prime}(\sigma) H(\sigma)-\left[H^{\prime}(\sigma)\right]^{2}}{[H(\sigma)]^{2}}-\frac{1}{(1-\sigma)^{2}}\right] \\
= & \frac{1}{1-\sigma}\left[e \frac{r+\alpha+b}{H(\sigma)}\left[\frac{H^{\prime}(\sigma)}{H(\sigma)}-\frac{1}{1-\sigma}\right]-\frac{\bar{w}+e-e_{u}}{1-\sigma}\right] \\
& +e \frac{r+\alpha+b}{H(\sigma)}\left[\frac{H^{\prime \prime}(\sigma) H(\sigma)-2\left[H^{\prime}(\sigma)\right]^{2}}{[H(\sigma)]^{2}}\right] .
\end{aligned}
$$

Any candidate $\sigma^{*}$ that satisfies $\Psi(\sigma)=0$ then has the property

$$
\Psi^{\prime}(\sigma)=e \frac{r+\alpha+b}{H(\sigma)}\left[\frac{H^{\prime \prime}(\sigma) H(\sigma)-2\left[H^{\prime}(\sigma)\right]^{2}}{[H(\sigma)]^{2}}\right]<0
$$

Thus, an interior solution for the optimum control intensity $\sigma$ exists, and it is unique. The no-shirking condition (12) then uniquely determines the related gross wage $w$. Last, at a given $\sigma$ and $w$, the input rule (9) uniquely determines employment. 


\section{B: Proof of Lemma 2}

Recalling that a locally stable equilibrium requires both $f_{1 \sigma} \leq 0$ and $f_{2 L} \leq 0$, the inequality $f_{1 \sigma} f_{2 L}-f_{1 L} f_{2 \sigma} \geq 0$ can be violated only if $\operatorname{sgn}\left[f_{1 L}\right]=\operatorname{sgn}\left[f_{2 \sigma}\right]$. Suppose that $f_{1 \sigma} f_{2 L}<f_{1 L} f_{2 \sigma}$.

If $f_{1 L}<0$, this would imply $\frac{f_{1 L}}{f_{1 \sigma}}>\frac{f_{2 L}}{f_{2 \sigma}}$, which is equivalent to $-\frac{f_{1 L}}{f_{1 \sigma}}<-\frac{f_{2 L}}{f_{2 \sigma}}$. Hence, we would have $\frac{d \sigma(L)}{d L}<\frac{1}{\frac{d L(\sigma)}{d \sigma}}<0$. Such a situation corresponds to an equilibrium which is only saddle-path stable, but not locally asymptotically stable (see, for example, the equilibrium $\left(\sigma_{2}, L_{2}\right)$ in Figure 4$)$.

Otherwise, if $f_{1 L}>0$ at the equilibrium, this would yield $\frac{f_{1 L}}{f_{1 \sigma}}<\frac{f_{2 L}}{f_{2 \sigma}}$, which is equivalent to $-\frac{f_{1 L}}{f_{1 \sigma}}>-\frac{f_{2 L}}{f_{2 \sigma}}$, implying that $\frac{d \sigma(L)}{d L}>\frac{1}{\frac{d L(\sigma)}{d \sigma}}>0$. Again, the equilibrium is only saddle-path stable, but not locally asymptotically stable (see, for example, the equilibrium $\left(\sigma_{2}, L_{2}\right)$ in Figure 5).

\section{C: Proof of Proposition 1}

Totally differentiating (28) and taking into account the proof of Lemma 1 yields

$$
\frac{\partial \sigma}{\partial e_{u}}=-\frac{\frac{\partial \Psi}{\partial e_{u}}}{\frac{\partial \Psi}{\partial \sigma}}=-\frac{1}{(1-\sigma) \frac{\partial \Psi}{\partial \sigma}}>0
$$

Note that $L$ can be eliminated from (10) by substituting for $\lambda$ from (11). Applying the implicit function theorem to (10) then yields

$$
\frac{\partial L}{\partial \sigma}=\frac{(1-t) L F^{\prime \prime}+e(r+\alpha+b) \frac{H H^{\prime \prime}-2 H\left(H^{\prime}\right)^{2}}{H^{3}}}{(1-t)(1-\sigma) F^{\prime \prime}}>0 .
$$

Moreover, we arrive at

$$
\begin{aligned}
\frac{\partial(1-\sigma) L}{\partial \sigma} & =(1-\sigma) \frac{\partial L}{\partial \sigma}-L \\
& =\frac{e(r+\alpha+b) \frac{H H^{\prime \prime}-2 H\left(H^{\prime}\right)^{2}}{H^{3}}}{(1-t) F^{\prime \prime}}>0 .
\end{aligned}
$$


Last, according to (9), it follows that

$$
\frac{\partial w}{\partial e_{u}}=-F^{\prime} \frac{\partial \sigma}{\partial e_{u}}+(1-\sigma) F^{\prime \prime} \frac{\partial(1-\sigma) L}{\partial e_{u}}<0 .
$$

\section{D: Proof of Proposition 2}

From the implicit function theorem, it follows that

$$
\frac{\partial \sigma}{\partial \alpha}=-\frac{\frac{\partial \Psi}{\partial \alpha}}{\frac{\partial \Psi}{\partial \sigma}}>0
$$

because $\frac{\partial \Psi}{\partial \alpha}=\frac{e}{H(\sigma)}\left[\frac{H^{\prime}(\sigma)}{H(\sigma)}-\frac{1}{1-\sigma}\right]>0$ holds if $\bar{w}+e-e_{u}>0$. Taking into account (12) then implies

$$
(1-t) \frac{\partial w}{\partial \alpha}=\frac{e}{H(\sigma)}-\frac{r+\alpha+b}{H(\sigma)} e \frac{H^{\prime}(\sigma)}{H(\sigma)} \frac{\partial \sigma}{\partial \alpha} .
$$

Evaluating $\frac{\partial \sigma}{\partial \alpha}$ yields

$$
\begin{aligned}
\frac{\partial \sigma}{\partial \alpha} & =-\frac{\frac{e}{H(\sigma)}\left[\frac{H^{\prime}(\sigma)}{H(\sigma)}-\frac{1}{1-\sigma}\right]}{e \frac{r+\alpha+b}{H(\sigma)}\left[\frac{H^{\prime \prime}(\sigma) H(\sigma)-2\left[H^{\prime}(\sigma)\right]^{2}}{[H(\sigma)]^{2}}\right]} \\
& =\frac{\frac{H^{\prime}(\sigma)}{H(\sigma)}-\frac{1}{1-\sigma}}{(r+\alpha+b)\left[\frac{2\left[H^{\prime}(\sigma)\right]^{2}-H^{\prime \prime}(\sigma) H(\sigma)}{[H(\sigma)]^{2}}\right]} .
\end{aligned}
$$

Therefore,

$$
(r+\alpha+b) \frac{H^{\prime}(\sigma)}{H(\sigma)} \frac{\partial \sigma}{\partial \alpha}=\frac{\left(\frac{H^{\prime}(\sigma)}{H(\sigma)}\right)^{2}-\frac{H^{\prime}(\sigma)}{H(\sigma)(1-\sigma)}}{\frac{2\left[H^{\prime}(\sigma)\right]^{2}-H^{\prime \prime}(\sigma) H(\sigma)}{[H(\sigma)]^{2}}}<1
$$

and $(1-t) \frac{\partial w}{\partial \alpha}>0$. With $\frac{\partial w}{\partial \alpha}>0$ and $\frac{\partial \sigma}{\partial \alpha}>0$, the falling level of productive employment can immediately be seen from the labor demand equation (9).

Note that (28), characterizing the optimum monitoring intensity, is unaffected by a variation in the tax rate as long as the job acquisition rate $\alpha$ is fixed. Hence, we have 
$\frac{\partial \sigma}{\partial t}=0$. Recalling the no-shirking condition (12), this implies a constant net wage $(1-t) w$ and an increasing gross wage $w$. With an unchanged monitoring intensity $\sigma$ and a rising wage $w$, total employment is reduced according to the input rule (9).

\section{E: Proof of Proposition 3}

Applying the implicit function theorem yields

$$
\begin{aligned}
\frac{\partial L}{\partial e_{u}} & =-\frac{f_{1 \sigma}}{\Delta}>0, \\
\frac{\partial \sigma}{\partial e_{u}} & =\frac{f_{1 L}}{\Delta}
\end{aligned}
$$

where $\Delta=f_{1 \sigma} f_{2 L}-f_{2 \sigma} f_{1 L}>0$ is immediate from the condition for the equilibrium to be stable. Evaluating the numerators leads to

$$
\begin{aligned}
f_{1 \sigma}= & (1-t) L F^{\prime \prime}+F^{\prime}(\bar{w}+m)(N-L) \frac{L F^{\prime}}{(F)^{2}} \\
& +e\left[r+b \frac{N}{N-L}\right] \frac{H H^{\prime \prime}-2\left(H^{\prime}\right)^{2}}{H^{3}} \\
f_{1 L}= & -(1-t)(1-\sigma) F^{\prime \prime}-F^{\prime}(\bar{w}+m) \frac{F+(N-L)(1-\sigma) F^{\prime}}{(F)^{2}} \\
& +\frac{e b N H^{\prime}}{(N-L)^{2} H^{2}} .
\end{aligned}
$$

Note that $f_{1 \sigma}<0$ is a sufficient stability condition, while $f_{1 L}$ can be rewritten as

$$
f_{1 L}=-\frac{f_{2 L}}{(1-\sigma)}+\frac{e b N}{H(N-L)^{2}}\left[\frac{H^{\prime}}{H}-\frac{1}{1-\sigma}\right],
$$

with

$$
\begin{aligned}
f_{2 L}= & (1-\sigma)^{2}(1-t) F^{\prime \prime} \\
& +(1-\sigma) F^{\prime}(\bar{w}+m) \frac{F+(N-L)(1-\sigma) F^{\prime}}{(F)^{2}}-\frac{e b N}{H(N-L)^{2}}
\end{aligned}
$$

The inequality $f_{2 L} \leq 0$ has to hold in any stable equilibrium. Further, combining the equilibrium conditions (17) and (18) reveals that

$$
\operatorname{sgn}\left[\frac{H^{\prime}}{H}-\frac{1}{1-\sigma}\right]=\operatorname{sgn}\left[\bar{w}+e-e_{u}\right]>0 .
$$


Thus, we arrive at $f_{1 L}>0$.

Noting that the no-shirking condition holds with equality, combining (5) and (8) yields

$$
V_{E}-V_{u}=\frac{e}{q}
$$

implying that $\frac{\partial\left[V_{E}-V_{u}\right]}{\partial e_{u}}=-\frac{e}{q^{2}} H^{\prime}(\sigma) \frac{\partial \sigma}{\partial e_{u}}<0$.

\section{F: Change of productive employment}

Productive employment evolves according to

$$
\frac{\partial(1-\sigma) L}{\partial e_{u}}=(1-\sigma) \frac{\partial L}{\partial e_{u}}-L \frac{\partial \sigma}{\partial e_{u}}
$$

Evaluating the derivatives yields

$$
\begin{aligned}
\operatorname{sgn}\left[\frac{\partial(1-\sigma) L}{\partial e_{u}}\right]= & \operatorname{sgn}\left[-L f_{1 L}-(1-\sigma) f_{1 \sigma}\right] \\
= & \operatorname{sgn}\left[(\bar{w}+m) \frac{L F^{\prime}}{F}-\frac{L e b N H^{\prime}}{(N-L)^{2} H^{2}}\right. \\
& \left.-(1-\sigma) e\left[r+b \frac{N}{N-L}\right] \frac{H H^{\prime \prime}-2\left(H^{\prime}\right)^{2}}{H^{3}}\right] .
\end{aligned}
$$

It can be demonstrated that the sign of the last expression is ambiguous. First, notice that $\left|H^{\prime \prime}\right|$ can be arbitrarily high at the equilibrium. In this case, the last term dominates the second one, and we arrive at $\frac{\partial(1-\sigma) L}{\partial e_{u}}>0$.

Substituting (18) into (17) yields

$$
-(1-t) F^{\prime}+\frac{H^{\prime}}{H}\left[(1-\sigma) F^{\prime}(1-t)-\left(\bar{w}+e-e_{u}\right)\right]=0 .
$$

Consider a situation in which $\bar{w} \rightarrow 0, m=0$, and $e_{u} \rightarrow e$. It follows that $H^{\prime} / H \rightarrow$ $1 /(1-\sigma)$. If, in addition, $r \rightarrow 0$ and $H^{\prime \prime} \rightarrow 0$ at the equilibrium, we obtain $\frac{\partial(1-\sigma) L}{\partial e_{u}}<0$ if $L /(N-L)>2$. The latter condition is equivalent to having an unemployment rate of $(N-L) / N<1 / 3$. Hence, given this specification, an unexpected reduction in productive employment turns out for any reasonable value of the unemployment rate. 


\section{References}

Besley, T. J., and S. Coate. 1992. Workfare versus welfare: Incentive arguments for work requirements in poverty-alleviation programs. American Economic Review 82: 249-261.

Besley, T. J., and S. Coate. 1995. The design of income maintenance programmes. Review of Economic Studies 62: 187-221.

Blackorby, C., and D. Donaldson. 1988. Cash versus kind, self-selection and efficient transfers. American Economic Review 78, 691-700.

Blank, R. M. 2002. Evaluating welfare reform in the United States. Journal of Economic Literature 40: 1105-1166.

Brett, C. 1998. Who should be on workfare? The use of work requirements as part of an optimal tax mix. Oxford Economic Papers 50: 607-622.

Chambers, R. G. 1989. Workfare or welfare? Journal of Public Economics 40: 79-97.

Coate, S. 1995. Altruism, the Samaritan's dilemma, and government transfer policy. American Economic Review 85: 46-57.

Cuff, K. 2000. Optimality of workfare with heterogeneous preferences. Canadian Journal of Economics 33: 149-174.

Dye, R. A., and R. Antle. 1986. Cost-minimizing welfare programs. Journal of Public Economics 30: 259-265.

Ellwood, D. T. 2000. Anti-poverty policy for families in the next century: From welfare to work - and worries. Journal of Economic Perspectives 14: 187-198.

Fredriksson, P., and B. Holmlund. 2003. Optimal unemployment insurance design: Time limits, monitoring, or workfare? CESifo Working Paper No. 1019, Munich.

Haveman, R., and B. Wolfe. 2000. Welfare to work in the U.S.: A model for other developed nations? International Tax and Public Finance 7: 95-114. 
Hotz, V. J., C. H. Mullin and J. K. Scholz. 2002. Welfare, employment and income: Evidence on the effects of benefit reduction from California. American Economic Review, Papers and Proceedings 92: 380-384.

Meier, V. 2002. Workfare in an efficiency wage model. CESifo Working Paper No. 674, Munich.

Moffitt, R. A. 1999. Explaining welfare reform: Public choice and the labor market. International Tax and Public Finance 6: 289-315.

Moffitt, R. A. 2002. The temporary assistance for needy families program. NBER Working Paper No. 8749, Cambridge, MA.

Peck, J., and N. Theodore. 2000. 'Work first': Workfare and the regulation of contingent labor markets. Cambridge Journal of Economics 24: 119-138.

Schöb, R. 2003. Workfare and trade unions: Labour market repercussions of welfare reform. CESifo Working Paper No. 942, Munich.

Shapiro, C., and J. E. Stiglitz. 1984. Equilibrium unemployment as a worker discipline device. American Economic Review 74: 433-444.

Solow, R. M. 1998. Work and Welfare. Princeton: Princeton University Press.

Thustrup Kreiner, C., and T. Tranæs. 2005. Optimal workfare with voluntary and involuntary unemployment. Scandinavian Journal of Economics 107: 459-474. 